Journal of Social Sciences (COES\&RJ-JSS)

ISSN (E): 2305-9249 ISSN (P): 2305-9494

Publisher: Centre of Excellence for Scientific \& Research Journalism, COES\&RJ LLC

Online Publication Date: $1^{\text {st }}$ July 2018

Online Issue: Volume 7, Number 3, July 2018

https://doi.org/10.25255/jss.2018.7.3.244.249

\title{
Students' Knowledge Regarding Oral Cancer at The University of Jordan: A Preliminary Study \\ Musab Masadeh
}

Oral and maxillofacial senior resident Jordan University Hospital, The University of Jordan, Amman, Jordan

\section{Article history:}

Received date $15^{\text {th }}$ January 2017, Accepted date $15^{\text {th }}$ June 2018, Published $1^{\text {st }}$ July 2018

\author{
Abstract: \\ Background: The aim of this study was to assess the level of awareness and knowledge \\ about signs and risk factors of oral cancer in the Jordan university student population as \\ a sample from Jordanian population.
}

Materials and Methods: A web-based questionnaire was administered through e-mails selected randomly from different collages provided by the university administration a 1month response period given for the questionnaire to be answered by replay with response rate $55 \%$ from 1000 email sent.

Results: Female to male ration $60 \%$ were females and $10 \%$ has good knowledge with no gender preferences $10 \%$ had a moderate knowledge about oral cancer and $60 \%$ has poor knowledge about oral cancer.

Conclusion: Overall, the awareness of oral cancer in the Jordan university student population was not satisfactory, pointing to a need for further dissemination of information on this issue and its associated risks.

Keywords: oral cancer, awareness and knowledge, signs and symptoms, risk factors.

Citation: Masadeh, Musab (2018). Students' Knowledge Regarding Oral Cancer at The University of Jordan: A Preliminary Study; Journal of Social Sciences (COES\&RJ-JSS), Vol. 7, No.3, pp.244-249; https://doi.org/10.25255/jss.2018.7.3.244.249. 


\section{Introduction}

Oral cancer is a serious disease worldwide, with up to 400000 new cases every year, and almost 130,000 deaths annually ${ }^{(1)}$. Incidence rates are much higher in developing regions like Southeast Asia, where they account for up to $50 \%$ of all malignant tumors ${ }^{(2) \text {. }}$

Oral cancer includes a large group of malignant neoplasms, of which squamous cell carcinoma is the most common form accounting for $95 \%$ of oral cancers. Risk factors for oral cancers include smoking, alcohol use, smokeless tobacco products, and HPV (human papillomavirus) infections, with smoking and alcohol having synergistic effects ${ }^{(3)}$.

The previously mentioned risk habits are very common in Jordan. Approximately half of the population (45\%) had smoked a cigarette in the past month, $40 \%$ in the past week, and $36 \%$ in past 24 hours ${ }^{(4)}$. This rate is considered one of the highest in the world. Majority of oral cancers have been observed to arise from long-standing premalignant lesions especially in high incidence areas ${ }^{(5)}$. Mouth cancer is largely preventable by avoiding known risk factors. National and international guidelines stress the importance of early detection ${ }^{(3)}$. Delayed presentation of oral cancer is mainly due to lack of public awareness of oral cancer and its associated risk factors, the results of which increasetreatment morbidity and reduces survival rates ${ }^{(6)}$.

Little is known about the awareness regarding oral cancer in Jordanian population. The objective of the present study was to determine the level of awareness of oral cancer, knowledge about early signs and the associated risk factors in a small community like university of Jordan students. The results obtained from this survey will assist to implement an effective health education program thereby helping to reduce the incidence rates of oral cancer.

\section{Materials and Methods}

A web-based questionnaire was administered through e-mails selected randomly from different collages provided by the university administration, with a 1-month response period given for the questionnaire to be answered by reply with response rate $55 \%$ from 1000 emails sent.

The questionnaire had 10 questions targeted for the age group, the gender, the awareness of oral cancer, the source of information about oral cancer and any signs or symptoms. The 550 replies were collected, exported as Excel File and analyzed.

\section{The questionnaire}

The web-based questionnaire has been devolved to be simple and approachable by most of the students, it consisted of 8 questions as follows

1- Are you a current Jordan university student?

2- Age group.

3- Gender.

4- Have you ever heard about Oral Cancer?

5- If yes, what is your source of information? 


\section{Students' Knowledge Regarding Oral Cancer at The University of Jordan}

6- Choose two risk factors for Oral cancer.

7- Choose one of the signs and symptoms of oral cancer.

8- Have you ever met any oral cancer patient?

\section{Results}

The response rate was $55 \%$ from the emails sent. $95 \%$ of the responses were fromcurrent students, $5 \%$ were not. The female responses were $80 \%$ and the males were $20 \%$. This might be due to higher number of female students in University of Jordan according to The JordanianDepartment of Statistics National Statistic Book in 2015, females in the University of Jordan were $66.3 \%$ compared to male students. See figure 1.

The age groups from the responses were $85 \%$ below of 21 years, $10 \%$ were between age of 21 and 30 years, 5\% were above 30 years. See figure 2 .

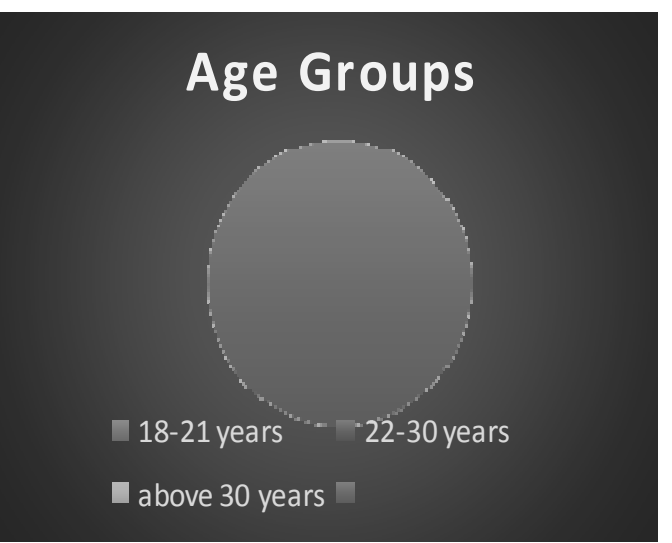

Figure 1

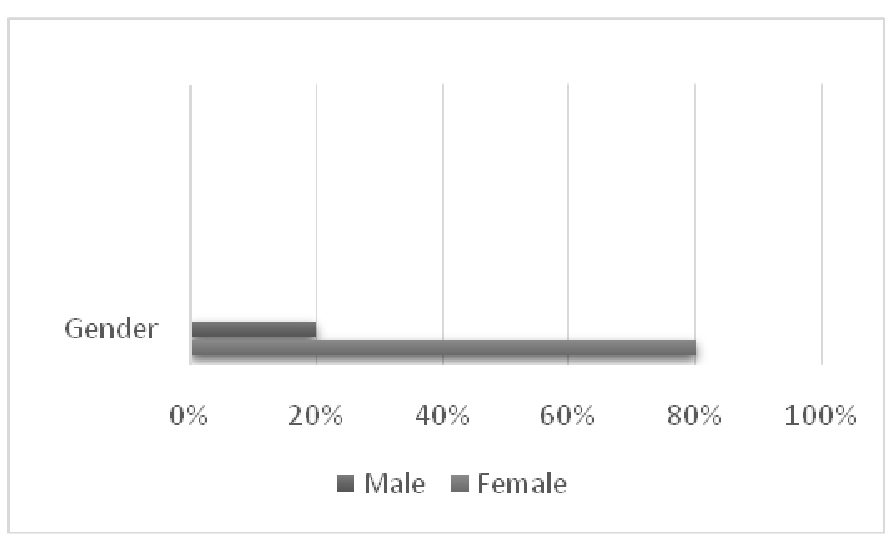

Figure 2 
There was a significant high number of students who heard about oral cancer with $90 \%$ who knew about oral cancer, of which they knew about it from their treating dentist, and $10 \%$ knew about it from other sources like Tv, inter net and press.

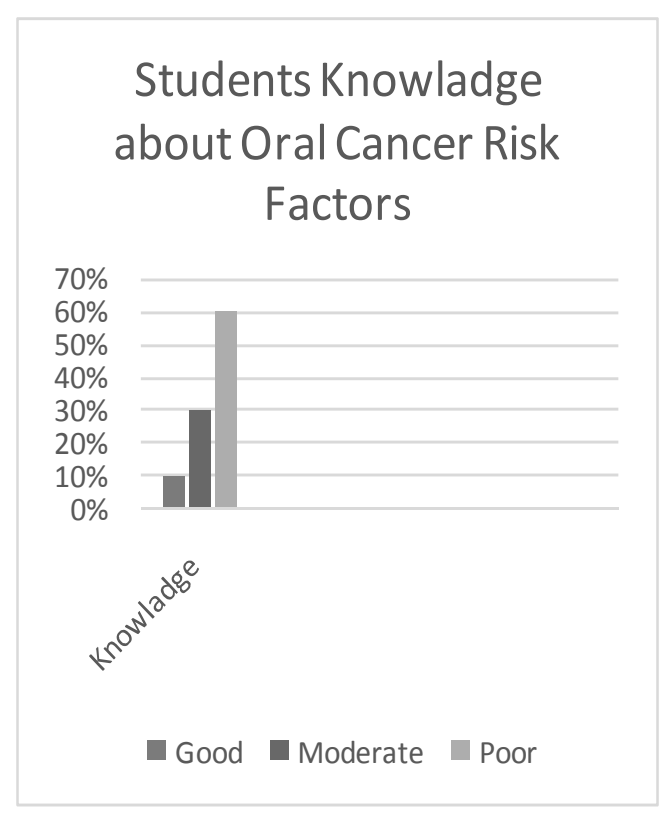

Figure 3

Out of the $80 \%$ of students who heared about oral cancer, $60 \%$ failed to address any risk factor to oral cancer, $30 \%$ had moderate knowledge about it, and only $10 \%$ had a good knowledge about oral cancer risk factors. See figure 3The students were asked about several oral cancer signs and symptoms, of which are longstanding oral ulcers, swelling in tongue with induration and redness in sub-lingual mucosa. $82 \%$ failed to address one of the signs or symptoms of oral cancer, and $92 \%$ of all participants never met any oral cancerpatient.

\section{Conclusion}

This was a preliminary study about the knowledge about oral cancer in Jordanian population. The sample was selected from the Jordan university student to prepare for a wider study to evaluate the true level of knowledge in Jordanian population and develop methods to increase the awareness about oral cancer and its risk factors. The use of simple form of questionnaire was to help the students to participate in the study, making the collection and analysis of the data more attainable.

The lack of knowledge about oral cancer risk factors was found to be significantly high through this sample. The high number of female subject could affect the overall results, which should be investigated more in farther studies. Early detection of oral cancer is the best prognostic measure for oral cancer patients. Poor knowledge about oral cancer 
signs and symptoms in general population leads to delay seeking medical treatment for such serious medical issue, which in return increases mortality and morbidity amongst oral cancer patients.

For future surveys it is of high importance to calculate sample size, with multi-centric sampling area with a correct distribution among general population to obtain more accurate results, detailed questions to provide the surveyor with more accurate results regarding the level of awareness the paper or interview-based surveys provide better response rates compared with web-based surveys, despite web-based surveys being faster and providing a higher number of participants. The role of public media written or seen is significant in educating the general population about oral cancer risk factors, and the importance of visiting a dentist if there was any change in the oral tissue for more than two weeks, which helps in early diagnosis and providing the proper treatment for such patients.

\section{Acknowledgments}

The author thanks the Jordan University administration for providing the e-mails of the students.

\section{Conflict of Interest}

The authors have declared that no conflict of interest exist. 
Journal of Social Sciences (COES\&RJ-JSS), 7(3), pp.244-249

\section{References}

1 Ferlay J, Shin HR, Bray F, et al (2010). Estimates of worldwide burden of cancer in 2008: GLOBOCAN 2008. Int J Cancer, 127, 2893-917.

2 Siegel R, Naishadham D, Jemal A (2012). Cancer statistics, 2012. CA Cancer J Clin, 62, 10-29.

3 Llewellyn CD, Johnson NW, Warnakulasuriya KA (2004). Risk factors for oral cancer in newly diagnosed patients aged 45 years and younger: a case-control study in Southern England. J Oral Pathol Med, 33, 525-32

4 Abughosh S1, WU IH, Hawari F., Peters RJ, Yang M., Crutchley R., Essien EJ. 2012, Cigarette smoking among Jordanian adults J Ethnsubst abuse. 2012;11(2):101-12.

5 Lumerman H, Freedman P, Kerpel S (1995). Oral epithelial dysplasia and the development of invasive squamous cell carcinoma. Oral Surg Oral Med Oral Pathol Oral RadiolEndod, 79, 321-9.

6 Warnakalasuriya KAAS, Harris CK, Scarrot DM, et al (1999). An alarming lack of public awareness towards oral cancer. BDJ, 187, 319-22. 